\title{
A Mathematical Model of the Covid-19 Cases in Indonesia (Under and Without Lockdown Enforcement)
}

\author{
Sugiyanto*, Muchammad Abrori \\ Department of Mathematics, Universitas Islam Negeri Sunan Kalijaga Yogyakarta \\ J1. Marsda Adisucipto No 1 Yogyakarta 55281, Indonesia. Tel. +62-274-540971, Fax. +62-274-519739 \\ Corresponding author* \\ sugimath@yahoo.co.id
}

Manuscript received: 29 March 2020. Revision accepted: 10 April, 2020. Published: 15 April, 2020.

\begin{abstract}
COVID-19 stands for Corona (CO), Virus (VI), Disease (D) and year 2019 (19), which is COVID-19 first appeared in 2019. Mathematical model of covid deployment in Indonesia under and without lockdown case uses the SIRV model, such as Susceptible, Infected, Recovery, and Virus. The results of this model state that under lockdown the spread of COVID-19 could be stopped. If it were not under lockdown it can multiply 1,276 times higher over two months.
\end{abstract}

Keywords: Corona virus novel 2019 (COVID-19); mathematics model; lockdown; Indonesia

\section{INTRODUCTION}

Novel corona virus can pneumonia (Pan et al., 2020). Pneumonia is an inflammatory lung disease which is characterized by coughing, chest pain, fever, and difficulty breathing. COVID-19 is a very contagious disease and declared by WHO as a pandemic on March, 12, 2020 (Chen et al., 2020). Pandemic is an infectious disease that is widely spread and it can reach all countries in the world. COVID-19 was first identified in Wuhan, Hubei Province, China in December 2019 (Liu et al., 2020). The understanding of lockdown in a pandemic context of COVID-19 is an emergency state where someone is not allowed to enter or out of a certain area in a certain period of time. This kind of action is carried out during the emergency situation ( $\mathrm{Ku}$ et al., 2020)

Mathematical model of COVID-19 deployment is using susceptible sub populations, infected, recovery and virus or abbreviated as SIRV. This population is divided into four subpopulations. Susceptible subpopulation (S) is a subpopulation that is vulnerable to COVID-19. Infected subpopulation (I) is subpopulation that is infected by COVID-19. Recovery subpopulation $(\mathrm{R})$ is subpopulation that recover from the COVID-19 virus. The population of COVID-19 (V) is the population number of COVID-19 outside the human body.

\section{MODEL FORMULATIONS}

The COVID-19 deployment model uses several parameters. Parameter $d_{1}$ is the rate of natural death and other diseases besides COVID-19. Parameter $a_{1}$ is the level of susceptibility to COVID-19 disease. parameter $a_{2}$ is the level of COVID-19 virus infection. Parameter $a_{3}$ is the cure rate of COVID-19 disease. Parameter $d_{2}$ is the death rate due to COVID-19 virus.

This models are defined into:

a. The susceptible subpopulation are affected by: (1) the increasing in birth rate; (2) the increasing in susceptible individuals from other regions; (3) the increasing number of individuals recovering from the diseases that is caused by COVID-19; (4) the reduce susceptibility of COVID-19 which infected individuals; (5) the reduce susceptible individuals going to other areas; (6) the loss of individuals due to natural deaths, other than diseases caused by COVID-19.

b. The infected subpopulation are affected by: (1) the increasing number of individual births from a mother that infected by COVID-19; (2) the increasing in individuals due to arrivals from other regions; (3) the increasing in individuals from susceptible and infected by COVID-19; (4) the reduce individual recovery from COVID-19; (5) the reduction in infected individuals who went to other areas; (6) the 
reduction in individuals who die from diseases that caused by COVID-19; (7) the loss of individuals due to deaths other than COVID-19.

c. The recovery subpopulation are affected by: (1) the increase in births at recovery time; (2) the increase in individual recovery from other regions; (3) the increase in infected; (4) the reduce susceptible individuals; (5) the reduction in recovery individuals that went to other areas; (6) the loss of individuals due to deaths other than COVID-19.

d. The population of COVID-19 (population of virus in the environment spread by infected people) are affected by: (1) the COVID-19 deployment because individuals are infected; (2) the unsurvive of COVID-19 in a free environment due to physical and chemical factors.

Table 1. The population, subpopulations, and parameters used in the COVID-19 spread by mathematics model.

\begin{tabular}{|c|c|c|c|}
\hline No. & Symbol & Explanation & Unit \\
\hline 1. & $S$ & Susceptible subpopulation & person $/ \mathrm{km}^{2}$ \\
\hline 2. & $I$ & Infected subpopulation & person $/ \mathrm{km}^{2}$ \\
\hline 3. & $R$ & Recovery subpopulation & person $/ \mathrm{km}^{2}$ \\
\hline 4. & $V$ & The population of COVID-19 & virus $/ \mathrm{km}^{2}$ \\
\hline 5. & $a_{1}$ & Birth rate of susceptible subpopulation & $d a y^{-1}$ \\
\hline 6. & $a_{2}$ & Birth rate of infected subpopulation & $d a y^{-1}$ \\
\hline 7. & $a_{3}$ & Birth rate of recovery subpopulation & $d a y^{-1}$ \\
\hline 8. & $b_{1}$ & Arrival rates from other countries susceptible subpopulation & $d a y^{-1}$ \\
\hline 9. & $b_{2}$ & Arrival rates from other countries infected subpopulation & $d a y^{-1}$ \\
\hline 10. & $b_{3}$ & Arrival rates from other countries recovery subpopulation & $d a y^{-1}$ \\
\hline 11. & $c$ & Death rates due to disease caused by COVID- 19 . & $d a y^{-1}$ \\
\hline 12. & $d_{1}$ & Natural death rates are not due to COVID-19 susceptible subpopulation. & $d a y^{-1}$ \\
\hline 13. & $d_{2}$ & Natural death rates are not due to COVID-19 infected subpopulation. & $d a y^{-1}$ \\
\hline 14. & $d_{3}$ & Natural death rates are not due to COVID-19 recovery subpopulation. & $d a y^{-1}$ \\
\hline 15. & $d_{4}$ & The COVID-19 mortality rates in environment. & $d a y^{-1}$ \\
\hline 16. & $e_{1}$ & Rates of traveling to other countries susceptible subpopulation & $d a y^{-1}$ \\
\hline 17. & $e_{2}$ & Rates of traveling to other countries infected subpopulation & $d a y^{-1}$ \\
\hline 18. & $e_{3}$ & Rates of traveling to other countries recovery subpopulation & $d a y^{-1}$ \\
\hline 19. & $f$ & The degree of COVID-19 emergence in environment & virus person ${ }^{-1}$ \\
\hline 20. & $k_{1}$ & Carrying capacity of the susceptible birth subpopulation & person $^{2}$ \\
\hline 21. & $k_{2}$ & Carrying capacity of the infected birth subpopulation & person $^{2}$ \\
\hline 22. & $k_{3}$ & Carrying capacity of the recovery birth subpopulation & person $^{2}$ \\
\hline 23. & $l_{1}$ & Carrying capacity of the susceptible natural death subpopulation & person $^{2}$ \\
\hline 24. & $l_{2}$ & Carrying capacity of the infected natural death subpopulation & person $^{2}$ \\
\hline 25 & $l_{3}$ & Carrying capacity of the recovery natural death subpopulation & person $^{2}$ \\
\hline 26. & $\alpha$ & The degree of interaction between susceptible subpopulation become infected subpopulation & $\mathrm{km}^{2} \cdot \mathrm{day}^{-1} \cdot$ virus $^{-1}$ \\
\hline 27. & $\beta$ & The degree of interaction betweem infected subpopulation become recovery subpopulation & $d a y^{-1}$ \\
\hline 28. & $\gamma$ & The degree of interaction between recovery subpopulation become susceptible subpopulation. & $d a y^{-1}$ \\
\hline
\end{tabular}

In this model it is assumed that: (1) open population, means people are free to enter and exit a country/region; (2) newborn individuals are included in the susceptible subpopulation; individuals who recover from covid are not immune; (3) every individual who infected by COVID-19 will become infected; (4) After the incubation period of two weeks are already considered an infected individual; (5) a vaccine for COVID-19 has not been found yet, it means that healing is due to good individual immunity, not because of vaccine; (6) people who recovery from COVID-19 can be a susceptible subpopulation again; (7) birth rate and natural mortality rate of the infected subpopulation and recovery does not exist.

In this model not analyzed local stability of the equilibrium point, and it become our next job. Figure 2 
is COVID-19 deployment transfer diagram. Based on the figure 2, Transfer Diagram, formed the COVID-19 spread mathematics model Equation (1a) - (1d).



Figure 1. COVID-19 Distribution between individuals.

$$
\begin{aligned}
& \frac{d S}{d t}=a_{1} S\left(1-\frac{S}{k_{1}}\right)+b_{1} S+\gamma R-\alpha S V-e_{1} S-d_{1} S\left(1-\frac{S}{l_{1}}\right) \\
& \frac{d I}{d t}=a_{2} I\left(1-\frac{I}{k_{2}}\right)+b_{2} I+\alpha S V-\beta I-c I-e_{2} I-d_{3} I\left(1-\frac{I}{l_{2}}\right) \\
& \frac{d R}{d t}=a_{3} R\left(1-\frac{R}{k_{3}}\right)+b_{3} R+\beta I-\gamma R-e_{3} R-d_{3} R\left(1-\frac{R}{l_{3}}\right) \\
& \frac{d V}{d t}=f a_{2} I\left(1-\frac{I}{k_{2}}\right)-d_{4} V
\end{aligned}
$$

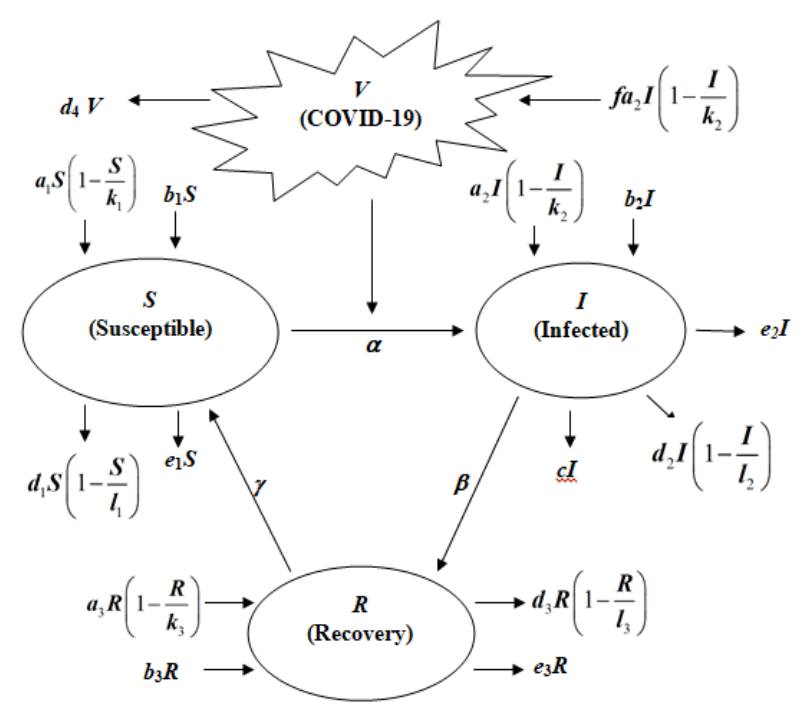

Figure 2. Transfer Diagram of COVID-19 Deployment Model.

\section{SIMULATION}

In this section, we will discuss about numerical simulation and its intepretation by COVID-19 deployment model. The initial value starts from the spread of COVID-19 in Indonesia on March, 12-23, 2020 that was announced by the Indonesian goverment. The initial value of the susceptible is taken from the total population of Indonesian divided by the population of Indonesian, $S_{0}=\frac{260,000,000}{260,000,000}=1$. The infected value was taken from the number of people infected on March 23, 2020 divided by the population of Indonesian, $I_{0}=$ $\frac{579}{260,000,000}=0.0000022269$. The recovery values is taken from the number of people recovered on March 23, 2020 divided by the total population of Indonesia, $R_{0}=\frac{30}{260,000,000}=0.0000001$. COVID-19 value is taken by the estimation, $V_{0}=\frac{1,000,000}{260,000,000}=$ 0.0038461538 .

The parameter values are as follows. Indonesia area $1.905 \times 10^{9} \mathrm{~km}^{2}$. In 2019, the birth rate is $=4.4 \times 10^{6}$ people. In 2019 , the mortality rate is $=1.6 \times 10^{6}$ people. There are 365 days in one year.

$$
\begin{gathered}
a_{1}=\frac{4.4 \times 10^{6}}{1.905 \times 10^{9} \times 365}=6.3 \times 10^{-3} d a y^{-1} \\
d_{1}=\frac{1.6 \times 10^{6}}{1.905 \times 10^{9} \times 365} d a y^{-1}=2.3 \times 10^{-3} d_{a y^{-1}}
\end{gathered}
$$

From the assumption of natural birth and death that the infected subpopulation does not exist, then the parameter $a_{2}=0$ and $d_{2}=0$. From the assumption of natural birth and death recovery subpopulation does not exist, then the parameter $a_{3}=0$ dan $d_{3}=0$. Because the Indonesia country has suspended its arrival visa and the other countries have also applied for a visa suspension, then the parameter $b_{1}=b_{2}=b_{3}=e_{1}=$ $e_{2}=e_{3}=0$.

From the Table 2, we take the highest gradient that is from March 17-18, 2020 are 14 souls per day (Zonautara, 2020). It means, the death rates due to the diseases caused by COVID-19 is the highest mortality divided by Indonesian population or $c=\frac{14}{260,000,000}=$ 0.0000000538 person $^{-2}$ day $^{-1}$. Value 260,000,000 are taken from the Indonesian population.

The value of COVID-19 mortality rates in the environment $(d)$ be accepted $d_{4}=\frac{2}{260,000,000}=$ $7.7 \times 10^{-9}$ day $^{-1}$ (BNPB, 2020).

The estimated value of COVID-19 emergence rate in the environment $(f)$ be accepted $f=\frac{260,000}{260,000,000}=$ $1 \times 10^{-3}$ virus person ${ }^{-1}$ day $^{-1}$.

The value of the level of interaction between susceptible subpopulation become infected subpopulation $(\alpha)$ taken from the slope of the highest infected divided by Indonesian population. The highest slope is on March, 18-19, 2020 or March, 20-23, 2020 there were 81 people died in one day. So, the value of $\alpha$ is 81 divided ten times of 579 people were infected (ten fold was infected but its unknown, because it's not COVID-19 tested),

$$
\alpha=\frac{81}{579 \times 10}=3.6 \times 10^{-3} \text { day }^{-1} \text { virus }^{-1} \text {. }
$$

The value of the level of interaction between recovery subpopulation become susceptible 
subpopulation $(\beta)$ taken from the highest slope recovery divided by the population of Indonesian. The highest slope was on March 21-22, 2020 as many as 9 people died in one day. So, the $\beta$ value is 9 divided by a hundred multiple of 30 people who recover (one hundred multiples are recovery but not known, because it does not test by COVID-19), $\quad \beta=\frac{9}{30 \times 100}=$ $3 \times 10^{-3}$ day $^{-1}$. The value of the level of interaction between recovery subpopulation become susceptible subpopulation $(\gamma)$ taken the same as $\beta$. The value of carrying capacity of natural birth and death in the susceptible sub population taken with an estimated number of deaths of 500,000 people divided Indonesian population, that is

$$
k_{1}=k_{2}=k_{3}=l_{1}=l_{2}=l_{3}=\frac{500,000}{260,000,000}=1.923 \times 10^{-3} .
$$

To summarize the parameter values, we shown in Table 3.

Table 2. The data that died in Indonesia because of COVID-19 (Zonautara, 2020).

\begin{tabular}{|c|c|c|c|c|}
\hline No. & $\begin{array}{l}\text { By the } \\
\text { date }\end{array}$ & $\begin{array}{c}\text { The } \\
\text { number of } \\
\text { people died }\end{array}$ & $\begin{array}{c}\text { The } \\
\text { number of } \\
\text { people } \\
\text { recovered }\end{array}$ & $\begin{array}{c}\text { The } \\
\text { number of } \\
\text { people } \\
\text { infected }\end{array}$ \\
\hline 1. & $\begin{array}{c}12 \text { March } \\
2020\end{array}$ & 1 & 4 & 34 \\
\hline 2. & $\begin{array}{c}13 \text { March } \\
2020\end{array}$ & 4 & 4 & 69 \\
\hline 3. & $\begin{array}{l}14 \text { March } \\
2020\end{array}$ & 5 & 5 & 96 \\
\hline 4. & $\begin{array}{c}15 \text { March } \\
2020\end{array}$ & 5 & 5 & 117 \\
\hline 5. & $\begin{array}{c}16 \text { March } \\
2020\end{array}$ & 5 & 8 & 134 \\
\hline 6. & $\begin{array}{c}17 \text { March } \\
2020\end{array}$ & 5 & 9 & 172 \\
\hline 7. & $\begin{array}{l}18 \text { March } \\
2020\end{array}$ & 19 & 11 & 227 \\
\hline 8. & $\begin{array}{l}19 \text { March } \\
2020\end{array}$ & 25 & 15 & 308 \\
\hline 9. & $\begin{array}{l}20 \text { March } \\
2020\end{array}$ & 32 & 17 & 369 \\
\hline 10. & $\begin{array}{l}21 \text { March } \\
2020\end{array}$ & 38 & 20 & 450 \\
\hline 11 & $\begin{array}{l}22 \text { March } \\
2020\end{array}$ & 48 & 29 & 514 \\
\hline 12 & $\begin{array}{c}23 \text { March } \\
2020\end{array}$ & 49 & 30 & 579 \\
\hline
\end{tabular}

Table 3 is multiplied by $260,000,000$ people; this number is taken from the Indonesian population. Lockdown case is the level of interaction between susceptible subpopulation become infected subpopulation, the degree of interaction between infected subpopulation becomes recovery subpopulation, and the degree of the interaction between recovery subpopulation being a susceptible subpopulation doesn not exist, it means the value of $\alpha=\beta=\gamma=0$.

Table 3. The parameter value without COVID-19 deployment lockdown in Indonesia.

\begin{tabular}{cll|lll}
\hline No. & Symbol & Value & No. & Symbol & Value \\
\hline 1. & $a_{1}$ & $6.3 \times 10^{-3}$ & 13. & $e_{2}$ & 0 \\
2. & $a_{2}$ & 0 & 14. & $e_{3}$ & 0 \\
3. & $a_{3}$ & 0 & 15. & $f$ & $1 \times 10^{-3}$ \\
4. & $b_{1}$ & 0 & 16. & $k_{1}$ & $1.923 \times 10^{-3}$ \\
5. & $b_{2}$ & 0 & 17. & $k_{2}$ & $1.923 \times 10^{-3}$ \\
6. & $b_{3}$ & 0 & 18. & $k_{3}$ & $1.923 \times 10^{-3}$ \\
7. & $c$ & $5.38 \times 10^{-8}$ & 19. & $l_{1}$ & $1.923 \times 10^{-3}$ \\
8. & $d_{1}$ & $2.3 \times 10^{-3}$ & 20. & $l_{2}$ & $1.923 \times 10^{-3}$ \\
& & & & & \\
9. & $d_{2}$ & 0 & 21. & $l_{3}$ & $1.923 \times 10^{-3}$ \\
10. & $d_{3}$ & 0 & 22. & $\alpha$ & $3.6 \times 10^{-3}$ \\
11. & $d_{4}$ & $7.7 \times 10^{-9}$ & 23. & $\beta$ & $3 \times 10^{-3}$ \\
12. & $e_{1}$ & 0 & 24. & $\gamma$ & $3 \times 10^{-3}$ \\
\hline
\end{tabular}

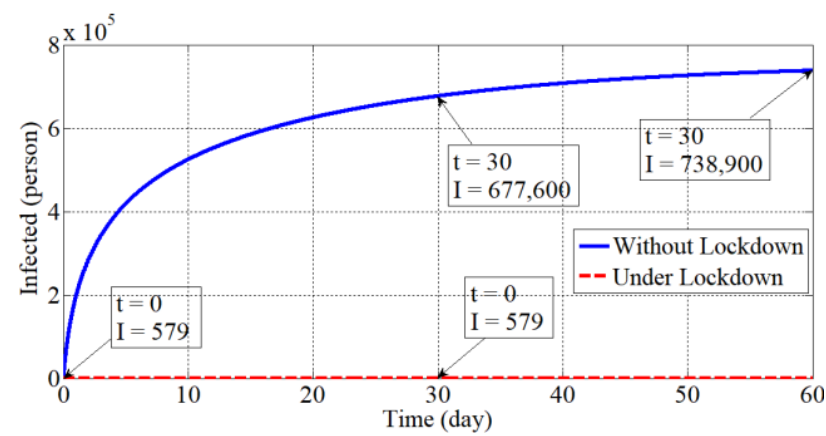

Figure 3. Diagram of Trajectory Subpopulation Infected between Under Lockdown and Without Lockdown.

Figure 3 shows the case trajectory diagram under and without lockdown in infected subpopulation. In the case of not lockdown on day-0 showed 579 people infected. On $30^{\text {th }}$ for the case to be 677,600 people infected. On $60^{\text {th }}$ showed 738,900 people infected. On day- 0 of lockdown case showed 579 people infected and the $30^{\text {th }}$ day showed 579 people infected. Because the incubation period of 14 days, then in the case of lockdown on the $15^{\text {th }}$ day no one has been infected.

\section{CONCLUSION}

Covid-19 is a vicious virus, because its spread from modeling result is very fast. From the Indonesia government's data on March 12-23, 2020 up to 579 
people have been infected, while from the model when not in lockdown of 579 people become 738,900 people have been infected. This is 1,276 times in two months. Under lockdown, it can minimize casualties because COVID-19 does not spread. Lockdown is a solution to reduce deaths due to COVID-19.

\section{REFERENCES}

BNPB, 2020 in https://www.covid19.go.id/ketahui-caramengurangi-risiko/ downloaded on March 20, 2020.

Chen, H., Guo, J., Wang, C., Luo, F., Yu, X., Zhang, W., ... \& Liao, J. (2020). Clinical characteristics and intrauterine vertical transmission potential of COVID-19 infection in nine pregnant women: a retrospective review of medical records. The Lancet.
Ku, C. C., Ng, T. C., \& Lin, H. H. (2020). Epidemiological benchmarks of the COVID-19 outbreak control in China after Wuhan's lockdown: a modelling study with an empirical approach. Available at SSRN 3544127.

Liu, Y., Gayle, A. A., Wilder-Smith, A., \& Rocklöv, J. (2020). The reproductive number of COVID-19 is higher compared to SARS coronavirus. Journal of travel medicine.

Pan, F., Ye, T., Sun, P., Gui, S., Liang, B., Li, L., ... \& Zheng, C. (2020). Time course of lung changes on chest CT during recovery from 2019 novel coronavirus (COVID-19) pneumonia. Radiology, 200370.

Zonautara, 2020 in https://zonautara.com/2020/03/22/tabelsebaran-virus-corona-per-provinsi-22-maret-2020/ downloaded on March 20, 2020. 
THIS PAGE INTENTIONALLY LEFT BLANK 